\title{
Smart Irrigation System for Optimized Use of Water and Energy
}

\author{
Dr H I Joshi ${ }^{1 *}$, P P Raval ${ }^{2}$ and Kush Patel ${ }^{3}$ \\ ${ }^{1,2}$ Lecturer, Department of Electrical Engineering R C Technical Institute, Ahmedabad, India. \\ ${ }^{3}$ Student, Department of Electrical Engineering $R$ C Technical Institute, Ahmedabad, India.
}

\begin{abstract}
Gross Domestic Product (GDP) of every country depends on its agriculture. Economy of any country also depends on its agriculture produce. Human population is incredibly rises in the world. To sustain the need of this rising population the requirement of water for farming as well as other various purposes will also rise. After completion of monsoon season, majority of irrigation is done by ground water. To lift this water for irrigation purpose lots of electricity is consumed. To cop up with rising demand of water for irrigation purpose, optimized use of it is desirable. To optimize the use of water for irrigation purpose some smart techniques should be implemented. Wastage of electricity during irrigation will also be reduced by optimizing the use of ground water for irrigation. When it is raining, irrigation must be stopped to save wastage of water as well as electricity. In this work smart irrigation system using microcontroller and sensors is presented to optimize the use of water for irrigation as well as reduce the wastage of electricity. The system presented in this work can be operated from anywhere in the world. It is not required for farmer to be present at farm for irrigation purpose. Farmer can operate the system and know the status of farm regarding irrigation at anytime from anywhere in the world using his mobile. This low cost smart irrigation system with some modification can also be applicable to gardens for optimized use of water and electricity.
\end{abstract}

Keywords: GDP, Smart irrigation, Ground water, Electricity, Microcontroller, Sensors

\section{INTRODUCTION}

It is required to achieve good yield, plant must be watered optimally. Unnecessary watering not only results in wastage of water but it also harms the plant. During monsoon season sometimes when it is raining, water pump is not timely turned off by mistake and due to this it results in wastage of ground water as well as electricity. Many countries in the world have less ground water resources. After completion of monsoon season, countries like India have to rely mostly on ground water. Level of ground water also reduces year by year in India. India has $17 \%$ of world's population but it has only $4 \%$ of the world's fresh water resources [1].

India is facing scarcity of water and this situation becomes worsen year by year. Its per capita water availability of 1544 cubic meters per year, as reported in 2011, has already fallen below the cutoff point of 1700 cubic meters, placing it among the water stressed nations of the world. This situation is likely to have worsened since 2011 and may continue to do so unless drastic reforms are undertaken to manage our scarce water resources more efficiently and in a sustainable manner [2]. Population of India rises so rapidly that according to the Central Water Commission (CWC), by 2050 the total water demand will overshoot supply in the country and the share of irrigation will come down to 68 per cent [3]. So use of water (particularly ground water) must be optimized.

$70 \%$ populations of India depend on agriculture for employment. After China, India is the second largest country in the world in the growth of population [4]. As majority Indians prefers vegetarian food, requirement of water for agriculture also rises day by day. As the resources of water cannot be increase as per the future need minimal or optimal use of water is the only way that all have to adopt in coming days.

For reducing the wastage of water advance techniques should be used that not only save human effort but electricity also [5]. Using microcontroller, soil humidity sensor, raindrop sensor and GSM modem low cost system can be made for automatic or smart irrigation. Using these components mobile operated user friendly system can be designed that doesn't require farmer to be present at farm for irrigation purpose. In many situations it is difficult and inconvenient for farmer to remain present at farm for irrigation. In many regions of India due to staggering of various types of loads, agriculture sector is given electrical power during late night or midnight. At this time it is dangerous to go to farm as reptiles and wild animals may also present in farm. So farmers should adopt such innovative techniques that can be operated through mobile and status of farm irrigation can also be received on mobile. Various types of innovative techniques for irrigation are mentioned in various literatures [6]. World population may cross 9.8 billion and scarcity of water will also increase so smarter techniques that not only save water but also provide comfort using Internet-of-Things (IoT) must be applied in various irrigation processes [7].

Due to advancement of Information and Communication technology and digital revolution, precision farming is possible now [8]. However availability of smart devices and communication system for agriculture purpose may raise cyber security issues and make such systems vulnerable for cyber attacks [9]. In future while designing the IoT based smart irrigation system such issues must be considered.

In this work a smart irrigation system is presented that uses microcontroller, soil moisture sensor, rain drop sensor, GSM module and other miscellaneous components. This low cost system allows user to operate it from anywhere so user need not to be present at farm for irrigation purpose. Status regarding irrigation can also be received on mobile. 


\section{PROPOSED SYSTEM}

The block diagram of the proposed system is presented here in Fig. 1. In proposed system ATMEGA328P microcontroller is used. Soil moisture sensor, rain drop sensor, LCD display, and GSM module are interfaced with ATMEGA328P microcontroller. Soil moisture sensor, raindrop sensor and dry run sensor (another soil moisture sensor is used for this purpose) give analog signals proportional to moisture level to the microcontroller.

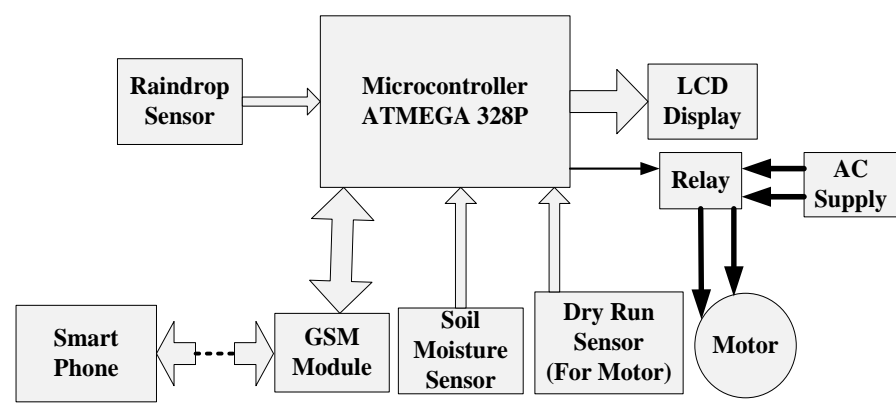

Fig. 1 Block diagram of proposed strategy

Microcontroller converts this analog data into digital value and compares the current data with set value of moisture level. If current value of soil moisture is more than the set value microcontroller sends signal to relay to turn off the submersible pump. Another moisture sensor or dry run sensor is used to sense the presence of outlet water of the submersible motor. If there is no water in the outlet pipe, submersible motor must be stopped otherwise it will be overheat. Raindrop sensor also gives analog data proportional to intensity of rain to the microcontroller. Microcontroller converts this analog data into digital value and decides the presence and intensity of rain. If it is raining sufficiently microcontroller sends signal to relay to turn off the submersible pump. This stops immediately unnecessary wastage of water as well as electricity. Using GSM module microcontroller receives the command sent by farmer. Through GSM module data regarding soil moisture and rain are sent to the user. Hence remote operation of the system becomes possible using GSM module. LCD display shows current status regarding soil moisture, rain and submersible pump.

\subsection{Description of hardware used}

The major components used in the system are described in short here.

Soil Moisture Sensor: This sensor senses the humidity or the moisture of the soil. The change in humidity is proportional to the amount of current flowing through the soil. It is presented in Fig.2. The same component is used as dry run sensor.

Microcontroller ATMEGA 328p: It has 14 digital input/ output pins (of which 6 can be used as PWM outputs), 6 analog inputs, a $16 \mathrm{MHz}$ quartz crystal, a USB connection, a power jack, an ICSP header and a reset button. This single chip 8 bit microcontroller has $32 \mathrm{~kb}$ flash memory with $\mathrm{read} / \mathrm{write}$ features. It has 32 general purpose working registers, and 3 flexible timer counters. It also has internalexternal interrupts and serial programmable USART. The pin configuration is shown in Fig. 3.

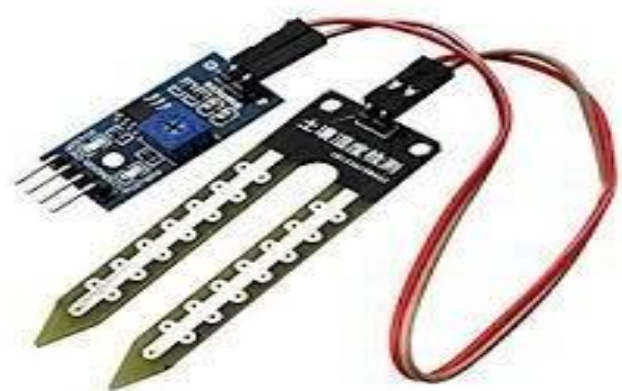

Fig. 2 Soil Moisture Sensor

\begin{tabular}{|c|c|c|}
\hline$\overline{(\text { RESET) PC6 } 1}$ & \multirow{14}{*}{ ATMEGA 328P } & \begin{tabular}{|l|l}
28 & $P C 5$ \\
\end{tabular} \\
\hline (RXD) PD0 2 & & $27 \mathrm{PC} 4$ (ADC4/SDA) \\
\hline (TXD) PD1 3 & & \begin{tabular}{|ll}
26 & $P C 3$
\end{tabular} (ADC3) \\
\hline (INTO) PD2 4 & & \begin{tabular}{|l|}
25 \\
PC2 (ADC2)
\end{tabular} \\
\hline (INT1) PD3 5 & & 24 PC1 (ADC1) \\
\hline (XCK/T0) PD4 6 & & $23 \mathrm{PCO}(\mathrm{ADC} 0)$ \\
\hline $\operatorname{vcc} 7$ & & \begin{tabular}{|l}
22 GND \\
\end{tabular} \\
\hline GND 8 & & \begin{tabular}{|l}
21 \\
\end{tabular} \\
\hline (XTAL1/TOSC1) PB6 9 & & 20 AVCC \\
\hline (XTAL2/TOSC2) PB7 10 & & 19 PB5 (SCK) \\
\hline (T1) PD5 11 & & \begin{tabular}{|ll}
18 & PB4 (MISO) \\
\end{tabular} \\
\hline (AIN0) PD6 12 & & 17 PB3 (MOSI/OC2) \\
\hline (AIN1) PD7 13 & & 16 PB2 $\overline{(S S} / O C 1 B)$ \\
\hline (ICP1) PB0 14 & & 15 PB1 (OC1A) \\
\hline
\end{tabular}

Fig. 3 Pin configuration of ATMEGA 328P

Raindrop sensor: It is a tool that senses presence as well as intensity of the rain. It consists of two modules, a rain board that detects the rain and a control module, which compares the analog value, which is given to the microcontroller. The raindrop sensors can be used in the automobile sector to control the windshield wipers automatically also can be used in the agriculture sector to sense presence of rain. It is presented in Fig. 4.

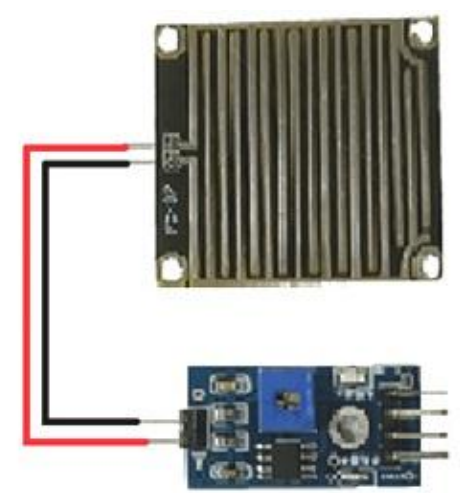

Fig.4 Raindrop sensor

GSM/GPRS Modem

It is a class of wireless modem, designed for communication over the GSM and GPRS network. Using AT commands data can be sent or received through this modem. It requires a SIM 
(Subscriber Identity Module) card just like mobile phones to activate communication with the network. It is presented in Fig.5.

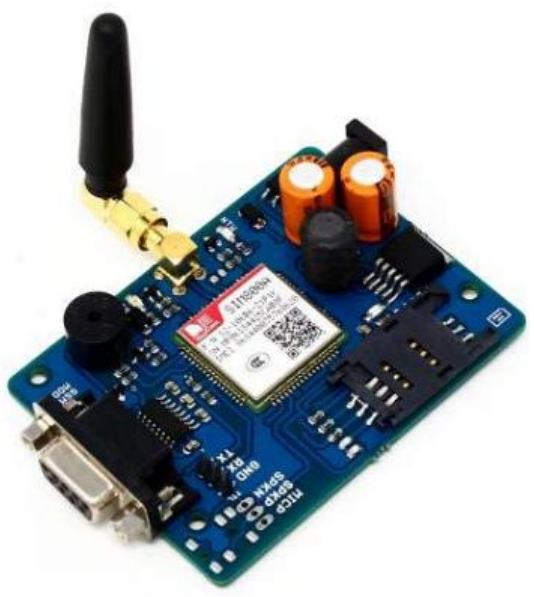

Fig. 5 GSM/GPRS modem

\section{LCD Display (16x2):}

This is used to display the current statistics of the system. It is shown in Fig. 6.

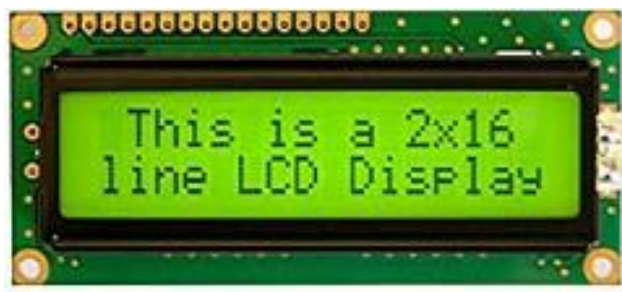

Fig. 6 LCD Display (16×2)

\section{Submersible Pump:}

Submersible pump having $18 \mathrm{~W}$ motor is used here for testing of the proposed system. It can lift the water up to 6 feet. It is shown in Fig. 7.

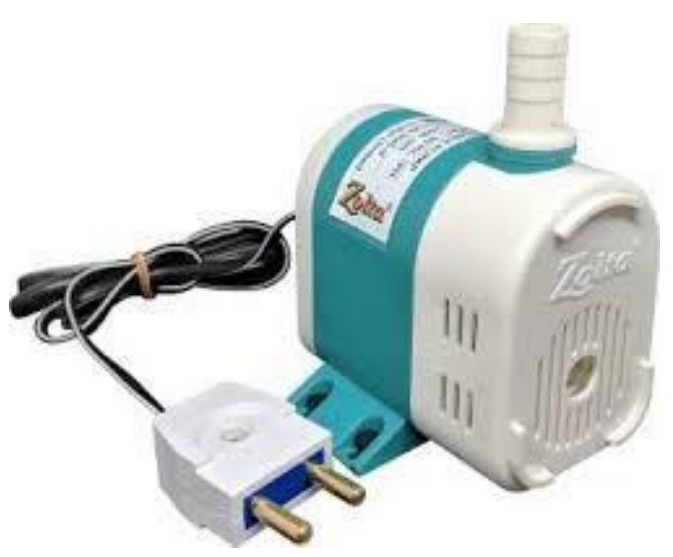

Fig. 7 Submersible pump

\subsection{Description of software used}

Arduino IDE 1.8.1 software is used in this work. It is the open source software which is used to make Arduino based code and it was uploaded to an Arduino Uno board.

\subsection{Flow chart of proposed smart irrigation system}

The flowchart based on which the microcontroller program is made is presented in Fig. 8. Microcontroller continuously checks for any message sent by user. Controller receives such messages (through GSM modem) and takes appropriate decisions. In some conditions if no any messages received from user, controller takes appropriate decision and then sent message regarding it to the user. User can know the status (of percentage soil moisture, submersible pump, rain etc.) by sending the SMS to system.

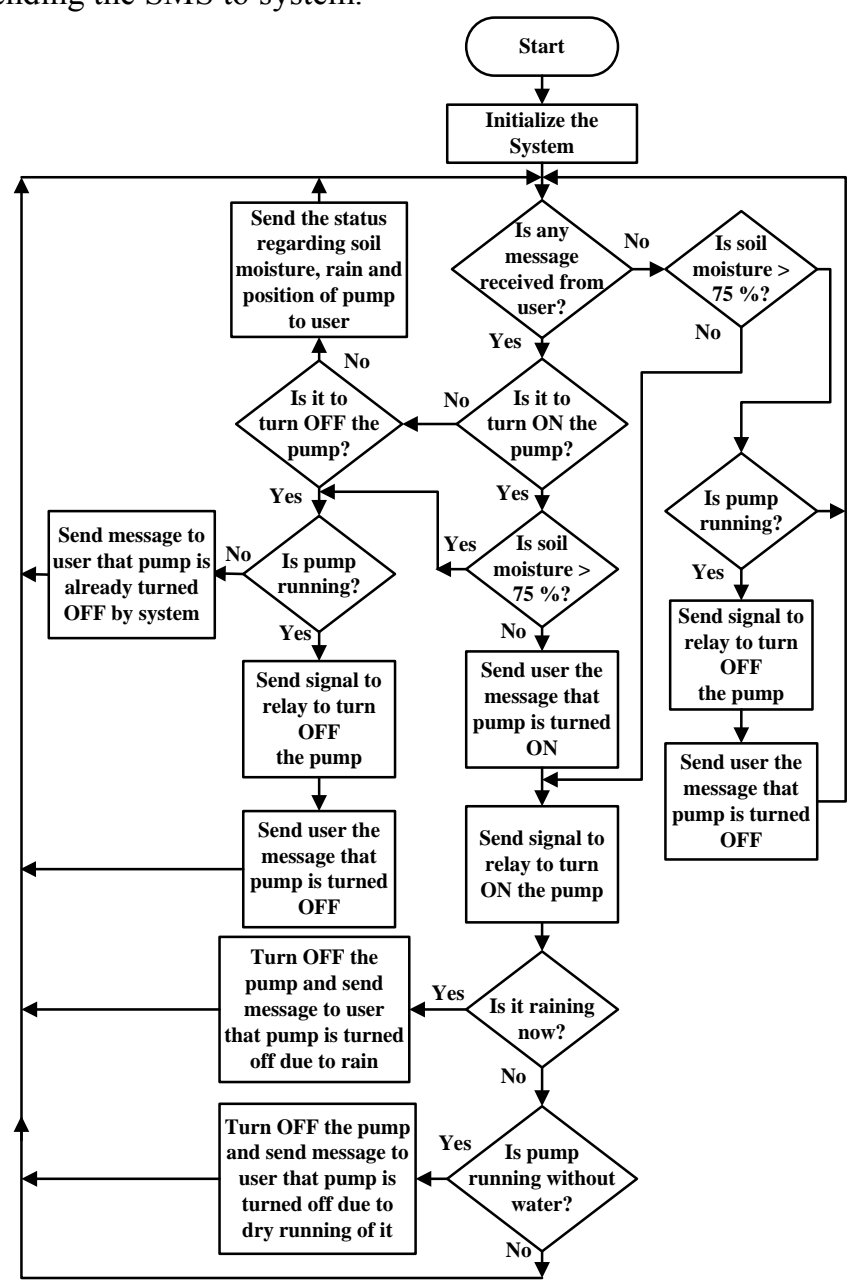

Fig. 8 Flow chart of proposed system

\section{TESTING OF SYSTEM}

The view of hardware made to realize the proposed strategy is depicted in Fig. 9. If user wants to turn on the submersible motor, he has to send the text "PON" to the system through SMS. Microcontroller checks this message and after checking the soil moisture level it sends signal in relay to turn on the submersible motor. If user wants to turn off the submersible motor, he has to send the text "POF" to the system through SMS. Microcontroller checks this message and sends signal in relay to turn off the submersible motor. This is presented in Fig. 10. The system was tested for various conditions. The set value of soil moisture is $75 \%$ in this work. Hence if soil moisture level becomes more than $75 \%$, pump automatically turns off and message regarding this event is sent to user on his mobile phone. Suppose submersible motor is running and 
suddenly rain starts, motor will turn off immediately and message regarding this event is sent to user on his mobile phone. If user is far away from the farm and wants to know the status of the farm, he has to send the text "STA" to the system through SMS. Microcontroller checks this message and sends various data regarding current status in reply to the user.

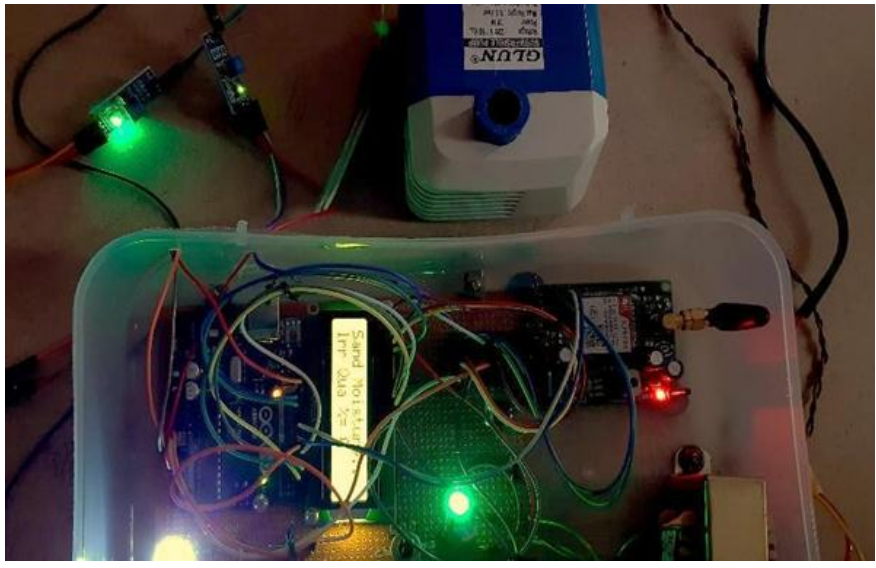

Fig. 9 View of hardware made for proposed system
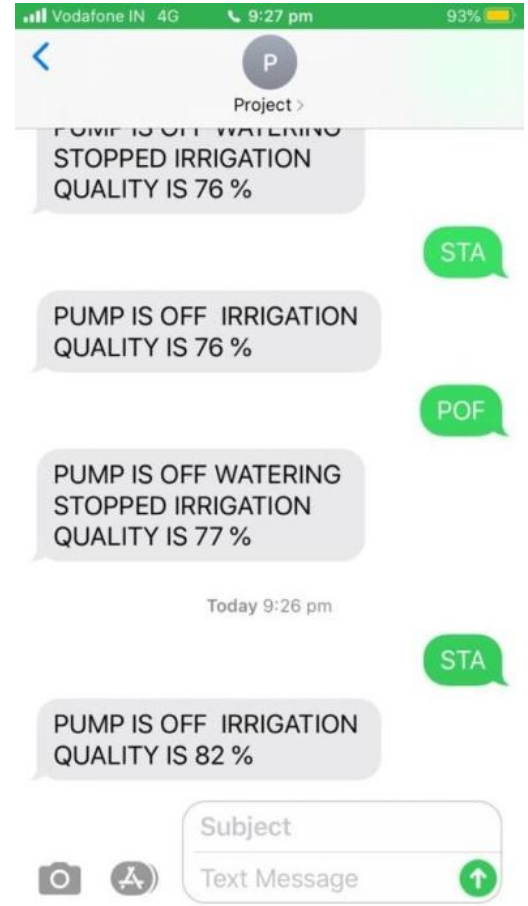

Fig. 10 Screen shot of users mobile showing various activities done by user

\section{CONCLUSION}

The system presented in this paper is useful for the optimal use of water in the farm. User can know the status at any time by sending the request through mobile phone. If submersible motor runs without water, moisture sensor will send signal immediately to microcontroller to prevent any damage to the motor.

This smart irrigation system is designed for small farm. However it can be designed with some modification for any size of farm. It can also be used for small or big gardens with some modifications. If flow sensor is used to measure consumption of water, data regarding actual usage of water can be send to user as well as to Government irrigation department for monitoring purpose.

\section{ACKNOLEDGMENT}

The authors gratefully acknowledge financial support from a Student Startup Innovation Policy (SSIP), Gujarat state for sanctioning research grant for this work.

\section{REFERENCES}

[1] Dr. Vibha Dhawan, "Water and Agriculture in India Background paper for the South Asia expert panel during the Global Forum for Food and Agriculture" Global Forum for Food and Agriculture (GFFA), 2017.

[2] L. S. Pereira, Theib Oweis, Abdelaziz Zairi, “A study on smart irrigation system using IOT", Agricultural Water Management, Volume 57, pp 175-206, April 2002.

[3] Bharat R. Sharma, Ashok Gulati, Gayathri Mohan, Stuti Manchanda, Indro Ray, and Upali Amarasinghe, "Water Productivity Mapping Of Major Indian Crops", NABARD report, 2018.

[4] Bobby Singla, Satish Mishra, Abhishek Singh, Shashank Yadav, "A study on smart irrigation system using IOT", International Journal of Advance Research, Ideas and Innovations in Technology, Volume 5, issue 2, pp 14161418, 2019.

[5] Miss. Mayuri Mali and Miss. Simran Mulla, "Study Paper On Smart Irrigation System", Mr. Dhanaji Baravade, International Journal Of Engineering Sciences \& Research Technology, Volume 8, issue 4, pp 99-102, April 2019.

[6] Bishnu Deo Kumar, Prachi Srivastava, Reetika Agrawaln and Vanya Tiwari, "Microcontroller Based Automatic Plant Irrigation System", International Research Journal of Engineering and Technology, Volume 4, issue 5, pp 1436-1439, May 2017.

[7] Muhammad Ayaz, Mohammad Ammad-Uddin, Zubair Sharif, Ali Mansour,And El-Hadi M. Aggoune,, "Internet-of-Things (IoT)-Based Smart Agriculture: Toward Making the Fields Talk", Special Section On New Technologies For Smart Farming 4.0: Research Challenges And Opportunities, IEEE Access.Volume 7, pp 129551-129583, September 2019.

[8] Shradha Verma, Anshul Bhatia, Anuradha Chug and Amit Prakash Singh, "Recent Advancements in Multimedia Big Data Computing for IoT Applications in Precision Agriculture: Opportunities", Multimedia Big Data Computing for IoT Applications: Concepts, Paradigms and Solutions, Volume 163, pp 391-416, Springer Nature Singapore Pte Ltd. 2020. 
International Journal of Applied Engineering Research ISSN 0973-4562 Volume 16, Number 2 (2021) pp. 161-165

(c) Research India Publications. https://dx.doi.org/10.37622/IJAER/16.2.2021.161-165

[9] Maanak Gupta, Mahmoud Abdelsalam, Sajad Khorsandroo, And Sudip Mittal, "Security and Privacy in Smart Farming:Challenges and Opportunities", IEEE Access.Volume 8, pp 34564-34584, February 2020. 